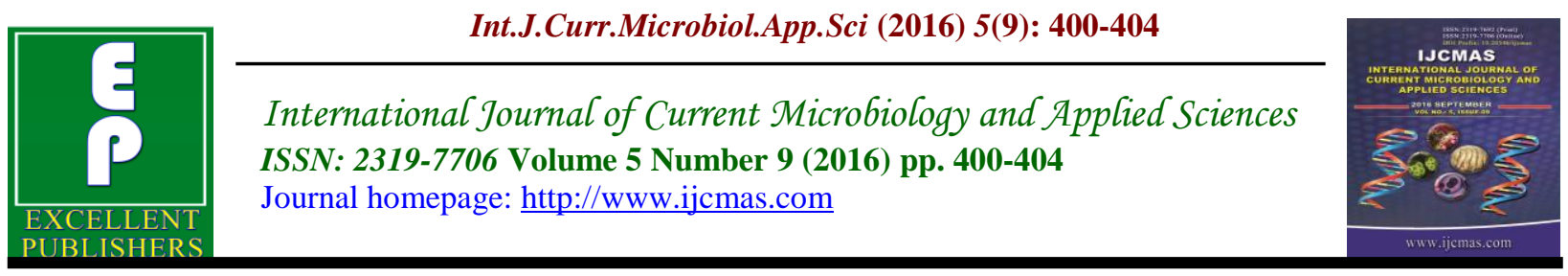

Original Research Article

http://dx.doi.org/10.20546/ijcmas.2016.509.043

\title{
Extended Spectrum $\beta$-lactamase (ESBL)-producing Klebsiella pneumoniae isolated from Burn Wound Infections
}

\author{
Khulood Abdulkareen Hussein*, Zainab Alag Hasan, Utoor Talib Jassim, \\ and Abdulameer Abdullah Al-Mussawi
}

College of Nursing, University of Basra, Basra, Iraq

*Corresponding author

\begin{abstract}
A B S T R A C T
Keywords

Extended-spectrum

$\beta$-lactamases

(ESBL),

Klebsiella

pneumoniae,

$\beta$-lactamases, burn infections, CHROMagar.

\begin{tabular}{l} 
Article Info \\
\hline Accepted: \\
15 August 2016 \\
Available Online: \\
10 September 2016
\end{tabular}

To detect the extended spectrum beta lactamase (ESBL) producing Klebsiella pneumoniae isolated from burn infections using phenotypic methods, and then testing their resistance against antibiotic. Forty two bacterial isolates were collected from infected burn wounds at burn center in Al-Fayhaa General Hospital in Basra city/Iraq, then cultured on MacConkey agar to detect Klebsiella, and then cultured on CHROM agar orientation to identify K. pneumoniae. Ninteen of K. Pneumonia isolates were screened for antibiotic resistance, including: Amoxicillin (AX), Doxycycline (DO), Gentamicin (CN), Amikacin (AK), and screening it for ESBL producing. $19(45.23 \%)$ isolates identified as K. pneumoniae, $15(78.9 \%)$ of them were ESBL producer and $4(21 \%)$ were ESBL nonproducer. All the nineteen isolates were resistant to Amoxicillin, 11 isolates to Doxycycline, 16 isolates to Gentamicin, and 18 isolates to Amikacin, while 15 isolates were ESBL resistant. Increasing prevalence of ESBL producing $K$. pneumoniae in nosocomial infections, especially in infected burn wounded this adds difficulty in curing post burn infections and may increase the rate of post burn mortality and morbidity. High number of isolates were antibiotics resistant, and this reflect the importance of implementation of susceptibility tests for successful treatment. Using CHROM agar media gives better results and faster in identifying ESBL.
\end{abstract}

\section{Introduction}

Klebsiella pneumoniae is a Gram-negative, nonmotile, encapsulated, lactose-fermenting, facultative anaerobic, rod-shaped bacterium. It is found in the normal flora of the mouth, skin, and intestines (Ryan et al., 2004), it can cause many infections like destructive changes to human and animal lungs if aspirated, specifically to the alveoli resulting in bloody sputum. Infection is the most common cause of morbidity and mortality in burned patients (Gomez et al., 2009). The type and quantity of microorganisms that colonize the burn wound may influence the risk of invasive wound infection. The pathogens that infect the wound are primarily gram-positive bacteria such as methicillin-resistant Staphylococcus aureus (MRSA) and gram-negative bacteria such as Acinetobacter baumannii-calcoaceticus complex, Pseudomonas aeruginosa, and 
Klebsiella species. These latter pathogens are notable for their increasing resistance to multiple antimicrobial agents (Keen et al., 2010; Albrecht et al., 2006).

Length of hospital stay and performance of invasive procedures are risk factors for acquisition of resistance strains.Current evidence implicates plasmids as the primary source of the resistance genes in Klebsiella species (Hudson et al., 2014). With the ability to produce extended-spectrum betalactamases (ESBL), Klebsiella is resistant to many classes of antibiotics. The most frequent are resistance to aminoglycosides, fluoroquinolones, tetracyclines, chloramphenicol and trimethoprim/ sulfamethoxazole (Nathisuwan et al., 2001).

Increasing the incidence of infections with extended-spectrum $\beta$-lactamase (ESBL)producing organisms has resulted in a therapeutic dilemma, as the choice of antibiotics is limited because of ESBL production (Paterson, 2000). The interactive effects of $\beta$-lactams are mediated through the inhibition of the bacterial cell wall and protein synthesis, respectively. Combination therapy with $\beta$-lactams and aminoglycosides is well accepted for the treatment of bacteremia caused by ESBL-producing $K$. pneumoniae isolates (Paterson et al., 2004) as well as other systemic infections (Korvick et al., 1992).

Prevent spreading Klebsiella infections between patients is a very important application, healthcare personnel must follow specific infection-control precautions (Guideline for Isolation Precautions: Preventing Transmission of Infectious Agents in Healthcare Settings (2007), including strict adherence to hand hygiene and wearing gowns and gloves when they dealing with patients with Klebsiella-related illnesses. Healthcare facilities also must follow strict cleaning procedures to prevent the spread of Klebsiella.

\section{Methodology}

Forty two bacterial isolates were collected from burn center in Al-Fayhaa General Hospital in Basra city Basra/ Iraq during the period from 01 March to 30 May 2015. Nineteen isolates were identified as Klebsiella by culturing on MacConkey agar, then identified as $K$. pneumoniae by culturing on CHROMagar Orientation (CHROM agar ${ }^{\mathrm{TM}}$, Paris, France) with supplement, then incubated aerobically at $37^{\circ} \mathrm{C}$ for 18 to $24 \mathrm{~h}$. Appearance of coloured colonies on the chromogenic medium was considered a positive test result.

Susceptibility against Amoxicillin (AX), Doxycycline (DO), Gentamicin (CN), Amikacin (AK) and Extended spectrum $\beta$ lactamase antibiotics by using ISBL CHROM agar (Paris, France).

\section{Results and Discussion}

A total of $19 / 42(45.23 \%) K$. pneumoniae isolates were obtained from infected burn wounds. K. pneumoniae colonies identified by morphological and biochemical characterization. Also CHROM agar Orientation was used for selective and differential colonies of $K$. pneumoniae.

Among 19 isolates of $K$. pneumoniae, $15(78.9 \%)$ isolates exhibited extended spectrum $\beta$-lactamase activity and showed metallic blue colonies on CHROMagar Orientation. The activities of 4antibioticsagainst isolates as shown in table (1), Figure (1).

In addition to pneumonia, Klebsiella can also cause infections in the urinary tract, lower biliary tract, and surgical wound sites. The range of clinical diseases includes pneumonia, thrombophlebitis, urinary tract infection, cholecystitis, diarrhea, 
upper respiratory tract infection, wound infection, osteomyelitis, meningitis, and

bacteremia and septicemia.

Table.1 Antibiotics sensitivity of $K$. pneumoniae isolates

\begin{tabular}{|r|r|r|r|r|r|}
\hline No. of & \multicolumn{5}{|c|}{ Antibiotics } \\
\cline { 2 - 6 } isolate & AX $(25 \mu \mathrm{g})$ & $\mathrm{DO}(30 \mu \mathrm{g})$ & $\mathrm{CN}(10 \mu \mathrm{g})$ & $\mathrm{AK}(10 \mu \mathrm{g})$ & $\mathrm{ISBL}$ \\
\hline 1 & $\mathrm{R}$ & $\mathrm{S}$ & $\mathrm{S}$ & $\mathrm{I}$ & $\mathrm{R}$ \\
\hline 2 & $\mathrm{R}$ & $\mathrm{I}$ & $\mathrm{R}$ & $\mathrm{R}$ & $\mathrm{R}$ \\
\hline 3 & $\mathrm{R}$ & $\mathrm{R}$ & $\mathrm{R}$ & $\mathrm{R}$ & $\mathrm{R}$ \\
\hline 4 & $\mathrm{R}$ & $\mathrm{R}$ & $\mathrm{R}$ & $\mathrm{R}$ & $\mathrm{R}$ \\
\hline 5 & $\mathrm{R}$ & $\mathrm{R}$ & $\mathrm{R}$ & $\mathrm{R}$ & $\mathrm{R}$ \\
\hline 6 & $\mathrm{R}$ & $\mathrm{S}$ & $\mathrm{S}$ & $\mathrm{S}$ & $\mathrm{S}$ \\
\hline 7 & $\mathrm{R}$ & $\mathrm{R}$ & $\mathrm{R}$ & $\mathrm{R}$ & $\mathrm{R}$ \\
\hline 8 & $\mathrm{R}$ & $\mathrm{R}$ & $\mathrm{R}$ & $\mathrm{R}$ & $\mathrm{R}$ \\
\hline 9 & $\mathrm{R}$ & $\mathrm{R}$ & $\mathrm{R}$ & $\mathrm{R}$ & $\mathrm{S}$ \\
\hline 10 & $\mathrm{R}$ & $\mathrm{I}$ & $\mathrm{R}$ & $\mathrm{R}$ & $\mathrm{S}$ \\
\hline 11 & $\mathrm{R}$ & $\mathrm{R}$ & $\mathrm{R}$ & $\mathrm{R}$ & $\mathrm{R}$ \\
\hline 12 & $\mathrm{R}$ & $\mathrm{R}$ & $\mathrm{R}$ & $\mathrm{R}$ & $\mathrm{R}$ \\
\hline 13 & $\mathrm{R}$ & $\mathrm{R}$ & $\mathrm{R}$ & $\mathrm{R}$ & $\mathrm{R}$ \\
\hline 14 & $\mathrm{R}$ & $\mathrm{I}$ & $\mathrm{R}$ & $\mathrm{R}$ & $\mathrm{R}$ \\
\hline 15 & $\mathrm{R}$ & $\mathrm{S}$ & $\mathrm{S}$ & $\mathrm{S}$ & $\mathrm{R}$ \\
\hline 16 & $\mathrm{R}$ & $\mathrm{R}$ & $\mathrm{R}$ & $\mathrm{R}$ & $\mathrm{R}$ \\
\hline 17 & $\mathrm{R}$ & $\mathrm{S}$ & $\mathrm{R}$ & $\mathrm{S}$ & $\mathrm{S}$ \\
\hline 18 & $\mathrm{R}$ & $\mathrm{S}$ & $\mathrm{R}$ & $\mathrm{S}$ & $\mathrm{R}$ \\
\hline 19 & $\mathrm{R}$ & $\mathrm{R}$ & $\mathrm{R}$ & $\mathrm{R}$ & $\mathrm{R}$ \\
\hline
\end{tabular}

$\mathrm{R}=$ Resistant, $\mathrm{S}=$ Susceptible, $\mathrm{I}=$ Intermediate *

Fig.1 Resistant isolates to $\mathrm{AX}, \mathrm{DO}, \mathrm{CN}$, and $\mathrm{AK}$ antibiotics
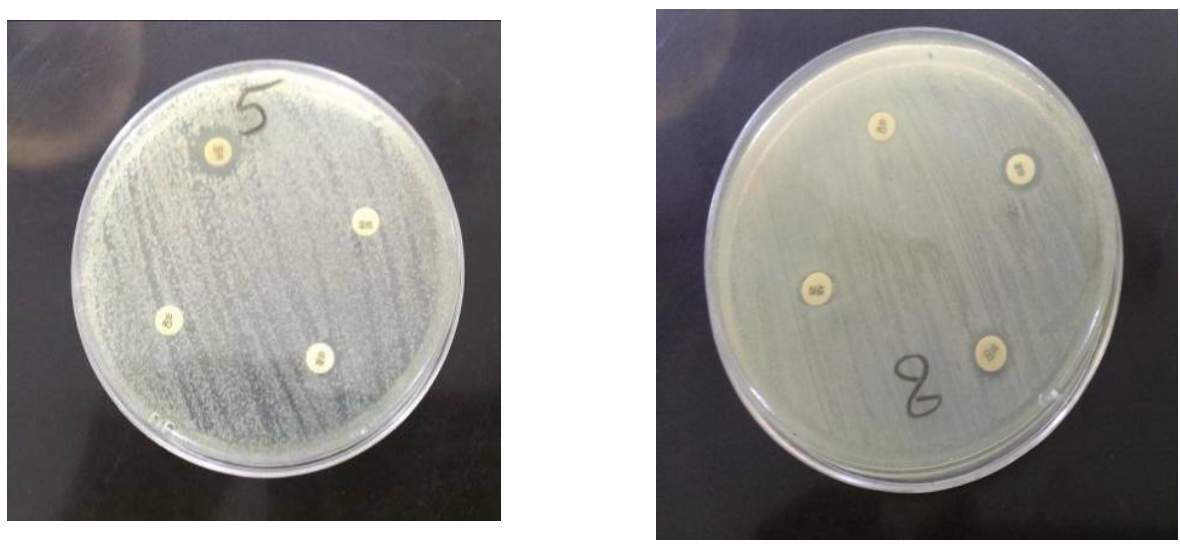
Fig.2 Metallic blue colonies of ESBL-producing K. pneumoniae on CHROMagar Orientation

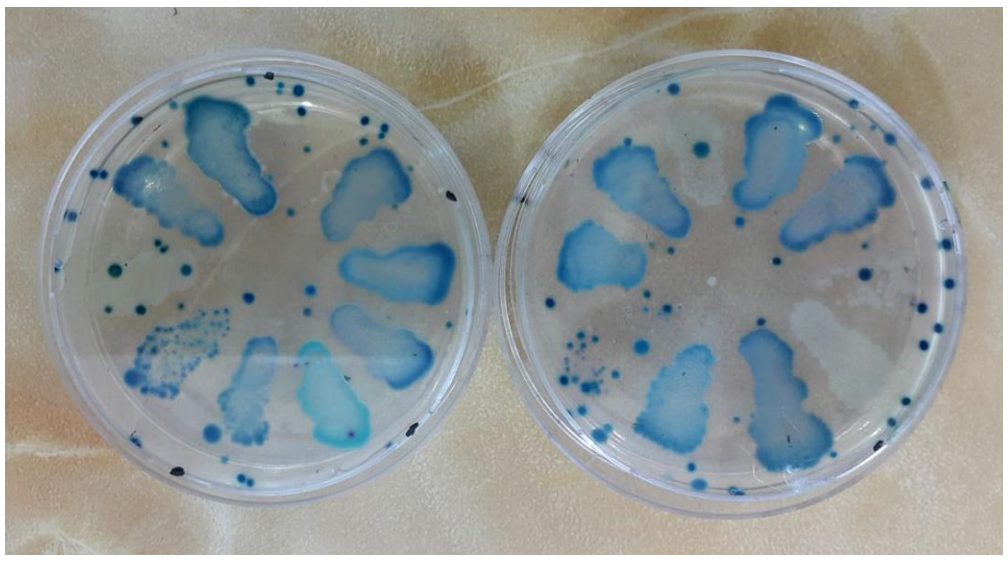

So treatment depends on the organ system involved and the choice of a specific antimicrobial agent depends on local susceptibility patterns because Klebsiella organisms are resistant to multiple antibiotics (Paneru, 2015).

Table (1) showed that all the nineteen isolates were resistant to Amoxicillin, 11isolates to Doxycycline, 16 isolates to Gentamicin, and 18 isolates to Amikacin, while 15 isolates were ISBL resistant.The high number of resistant isolates reflect the importance of implementation of susceptibility tests for successful treatment.

Agents with high intrinsic activity against $K$. pneumoniae should be selected for severely ill patients. Examples of such agents include third-generation cephalosporins (eg, cefotaxime, ceftriaxone), carbapenems (eg, imipenem/cilastatin), aminoglycosides (eg, gentamicin, amikacin), and quinolones. These agents may be used as monotherapy or combination therapy. Some experts recommend using a combination of an aminoglycoside and a third-generation cephalosporin as treatment for non-ESBLproducing isolates. Others disagree and recommend monotherapy.

\section{References}

Albrecht, M.C., Griffith, M.E., Murray, C.K., Chung, K.K., Horvath, E.E., Ward, J.A. 2006. Impact of Acinetobacter infection on the mortality of burn patients. J. Am. Coll. Surg., 203: 546-50.

Gomez, R., Murray, C.K., Hospenthal, D.R., Cancio, L.C., Renz, E.M., Holcomb, J.B., et al. 2009. Causes of mortality by autopsy findings of combat casualties and civilian patients admitted to a burn unit. J. Am. Coll. Surg., 208(3): 348-54.

Guideline for Isolation Precautions. 2007. Preventing Transmission of Infectious Agents in Healthcare Settings. Centers for Dis. Control and Prevention.

Hudson, Corey, Bent, Zachary, Meagher, Robert, Williams, Kelly. 2014. "Resistance Determinants and Mobile Genetic Elements of an NDM1-Encoding Klebsiella pneumoniae Strain".

Keen, E.F. 3rd, Robinson, B.J., Hospenthal, D.R., et al. 2010. Prevalence of multidrug-resistant organisms recovered at a military burn center. Burns, 36: 819-25.

Korvick, J.A., C.S. Bryan, B. Farber, T.R. 
Beam, Jr., L. Schenfeld, R.R. Muder, D. Weinbaum, R. Lumish, D.N. Gerding, and M.M. Wagener. 1992. Prospective observational study of Klebsiella bacteremia in 230 patients: outcome for antibiotic combinations versus monotherapy. Antimicrob. Agents Chemother., 36: 2639-2644.

Nathisuwan, S., Burgess, D.S., Lewis, J.S. 2001. "Extended-Spectrum $\beta$ Lactamases: Epidemiology, Detection, andTreatment". Pharmacother., 21(8): 920-928.

Paneru, T.P. 2015. Surveillance of Klebsiella pneumoniae and antibiotic resistance a retrospective and comparative study through a period in Nepal. Danish J. Med. Biol. Sci., 2936.
Paterson, D.L. 2000. Recommendation for treatment of severe infections caused by Enterobacteriaceae producing extended-spectrum beta-lactamases (ESBLs). Clin. Microbiol. Infect., 6:460-463.

Paterson, D.L., W.C. Ko, A. Von Gottberg, S. Mohapatra, J.M., Casellas, H., Goossens, L. Mulazimoglu, G. Trenholme, K.P., Klugman, R. A. Bonomo, L.B. Rice, M.M. Wagener, J.G. McCormack, and V.L. Yu. 2004. Antibiotic therapy for Klebsiella pneumoniae bacteremia: implications of production of extended-spectrum beta-lactamases. Clin. Infect. Dis., 39: 31-37.

Ryan, K.J., Ray, C.G., eds. 2004. Sherris Medical Microbiology (4th ed.). McGraw Hill.

\section{How to cite this article:}

Khulood Abdulkareen Hussein, Zainab Alag Hasan, Utoor Talib Jassim and Abdulameer Abdullah Al-Mussawi. 2016. Extended Spectrum $\beta$-lactamase (ESBL)-producing Klebsiella pneumoniae isolated from Burn Wound Infections. Int.J.Curr.Microbiol.App.Sci. 5(9): 400404. doi: http://dx.doi.org/10.20546/ijcmas.2016.509.043 